\title{
Current trends: Operative Strategy for the Management of Cervical Radiculopathy
}

\author{
Santosh K Bashyal, MD, PhD ${ }^{1}$, Saroj K Bashyal, BDS ${ }^{2}$, Dristi Bashyal, MD ${ }^{3}$, Rakesh Kumar Suman, MS ${ }^{4}$ \\ ${ }^{1}$ Department of Orthopaedics, The Second Affiliated Hospital, Chongqing Medical University, No. 76 Linjiang Road, District Yuzhong, \\ Chongqing,400010, China
}

${ }^{2}$ Department of Dental Surgery, Universal Dental Hospital and Research Center, Kalanki, Kathmandu, Nepal

\author{
${ }^{3}$ Department of Emergency Medicine, Kathmandu Hospital and Research Center, National cancer hospital, Kathmandu, Nepal \\ ${ }^{4}$ Department of TCM, The Second Affiliated Hospital, Chongqing Medical University, No. 76 Linjiang Road, District Yuzhong, \\ Chongqing,400010, China
}

(Santosh and Saroj are principle author)

\begin{abstract}
Background: Endoscopic Cervical Discectomy has replaced many open fusion related surgery and bone grafting. Endoscopic surgery is without the placement of retractor and only need a working sheath diameter of about 7 mm incision, which is simple, easy to access with proper visualization. Minimal invasive surgery helped advancement in surgery by improvement in visualization. Depend on extend of lesion, type of compressive pathology curvature of the spine and presence of instability Surgeon choice the approaches. This newer approaches for radiculopathy help to decompress the neural elements and disc pathology preserving spinal motion and stability. It also helped to reduce the iatrogenic and for vertebral artery injuries. Methods: PubMed database, English literature, original articles, case reports, Operative technique reviewed. Focus articles related to the approaches of the cervical radiculopathy, current successful treatments replacing older open methods. Inclusion criteria pre-operative, post operative planning, Operative preparation, VAS score, intra -operative and endoscopic. Excluded criteria long term follow up data, bio-motion study in cadavers. Result: Degeneration of uncovertrebral and zygopophyseal joints lead to foraminal entrapment of spinal nerve roots and disc herniation. Preoperative history, dynamic cervical extension-flexion, PET CT scan and MRI, Endoscopic Cervical Discectomy have replaced many open fusion related surgery and bone grafting.It works on placement of retractor, sheath diameter of about 7 mm incision which is easy access with proper visualization Fluoroscopic guided endoscopic surgery reduces iatrogenic tissue damage, postoperative pain, disability and return back to work early..Anterior approaches includes discectomy or corpectomy while posterior involves laminectomy with or without fusion and laminoplasty in spinal cord decompression. Open traditional surgical compared to newer minimal invasive surgery was much prolong hospital stay and delay healing. Conclusion: Proper visualization transform the spinal surgery reduces surgery related complication.Understanding surgical anatomy and reevaluation of cases helps to reduce vascular damage in anomaly position.
\end{abstract}

Keywords: Cervical radiculopathy, Operative strategy, Minimal invasive surgery; Endoscopic surgery, Decompression

\section{Background}

Cervical radiculopathy is caused by compression of spinal nerve roots due to disc herniation, spondylosis, instability, trauma or rarely tumors. Due to compressive pathology patients present with sensorimotor deficit syndrome like neck pain, numbness, and /or tingling sensation in upper extremities.[1,2]. The purpose of this review is to address some questions. What are the current surgical planning and treatment options for the patient with cervical radiculopathy ?How did the surgical skill changed and transformed from past to present? What are the determining key structures and points to be implemented for successful surgery technique? Cervical osteophytes are associated with radiculopathy which causes dysphasia, severe pain and aspiration which compress esophagus, nerve root and pharynx .[3,4]. The presence of osteophtyes is related to increase risk of foreign body impaction .Most of the surgeries with traditional procedure and microendoscopic surgery are rely on direct visualization to access the target pathology for adequate decompression .Due to progressive development of the spinal endoscopic technique in recent year helped quality treatment after failed conservative and traditional therapy.
The Endoscopic surgery can be done from anterior transdiscal approach and the posterior interlaminar access. The main purpose of the clinician is to rapid diagnosis and treatment of the symptomatic pathology, return to normal activities with less hospital stay.

\section{Methods}

To get adequate information and sufficient data, we search PubMed database till 2016 September. It was confirmed to English languages literature only .We approach our study to specific current topics. Through search engine in database we use term at first "Operative treatment of cervical radiculopathy". The search was total 427 articles, we use modern scientific library of first affiliated hospital of Chongqing medical university where almost $90 \mathrm{pc}$ articles can be downloaded and can access full text. Then to find specific and targeted articles we use subgroup as "MIS,Surgical approaches for cervical radiculpathy " then articles was confirmed to 46 . Then again to make it more specific and useful articles for our review we again use some key word "Current operative treatment of cervical radiculopathy "then useful articles were narrowed to 24 . We review all the relevant full text manuscripts from PubMed 


\section{International Journal of Science and Research (IJSR) \\ ISSN (Online): 2319-7064}

Index Copernicus Value (2015): 78.96 | Impact Factor (2015): 6.391

using keywords and each citation from references reviewed by independent author. We focus mainly on Operative preparation during surgery, VAS score, intra -operative and endoscopic parameters. We excluded long term follow up data, bio-motion study of study in cadavers.

\section{Indications for Surgery}

Inclusion criteria for surgery are failed non operative, herbal, alternative treatment, clinically significant motor deficits, excoriating pain, instability in the setting of disabling radiculopathy. The decision for surgery is based on Physical examination, radiological changes, severity and duration of symptoms. Failed conservative treatment includes physiotherapy, analgesic, NSAIDS, Epidural analgesic. Emergency surgery includes new onset gait disturbance, bowel bladder dysfunction and rapid progression of diseases. Spinal alignments, stability, balance and Surgeon skills are all factors that decides which operation to perform [5] Surgical approaches can be grouped into two types anterior and posterior.

\section{Operative technique, planning, strategies and outcomes}

Imaging, Electro-physiologic examination play important role in diagnosing and localizing the radiculopathy symptoms. Dynamic Cervical spine Lateral -Extension view, CT and MRI are important examination before and after surgery . CT scan is the most sensitive test for bony structure of the spine like abnormal bony destruction, bone formation -Osteophytes. PET scan help localize and diagnose bony opening of the foramina may be osteophytes formation which causes nerve root impingements. Combined CT and Myelography helps to localize and delineate nerve root but inadequate visualization of soft tissue structures. MRI T2 hyper intensity /T1 hypo-intensity is a good tool to show soft tissue structures and nerve that exit the foramen.

Another important parameter for diagnosis in localizing the correct level of pathology in patient with vague symptoms.[6] This has poor predictive capacity in showing nerve root compression.

Ashkan, et,al found that only $42 \mathrm{pc}$ of patients with positive EMG had compressive pathology.

In 1931 Burman introduced first concept and method of myeloscopy as a direct visualization of spinal cord[7].Later his work was carried out by pool(1938) by performing 400 myeloscopic procedure with insertion of large bore into Dura cavity but had many mortality $[8,9]$.

The progression and method of surgical management gradually transformed. 1928 Stookey described anatomical location of cervical disc herniation and later mixter and Barr performed laminectomy and disc excision to relieve radiculopathy pain [10, 11]. In 1955, 1958 Cloward, Robertson and smith first experienced anterior cervical discectomy without bone fusion by direct decompressing the osteophytes that compress spinal nerves and disc fragments.[12,13,14]
Most of the author described their experiences in endoscopic surgery that helps to preserve the functional motion of cervical spines and its stability though removing underlying structure. Through various microsurgical approach either posterior prone position or anterior supine position choice for surgery. 1996 Jho performed anterior cervical microforaminotomy approach through endoscopic method where he directly visualize the structure and removed pathology like osteophytes and decompress the nerve which causes radiculopathy without bony fusion and preserving the motion segments of cervical spines.[15,16].In 2006 Korinth compared the anterior and posterior surgical approaches in 293 patients for soft tissue herniation and concluded relatively anterior method is safe in damaging the structure and easy access without much tissues injury.[17,18]. Posterior approaches is mainly for multilevel spine decompression and laminectomy with or without fuson and laminoplasty. One study by jadickie and Korinth et all in 2003 found the outcome for posterior approach was $80 \mathrm{pc}$.

Introduction of PCD helped to remove the structure and compressing pathology without damaging much more structure. Onik,et .al, removed only the portion of disc during PCD to decompress spine nerve root which improved the radiculopathy pain .[19]

One of the study done through transforaminal lateral interbody fusion minimal invasive technique concluded as less entry points for microbes, less muscle dissection and dead space compared to traditional open surgery [20]. Endoscopic has become major role neurosurgeon and orthopedic surgery to deal with spine, spine related problem and tumor .Ooi et,al,in cases of chronic arachnoiditis due to nerve entrapments used endoscopic system to treat stenosis cases by direct intra-theca pathology before surgery [21,22]. Deng et.al, performed anterior transcorporeal approach of percutaneous endoscopic cervical discectomy for disc herniation at the C4-C5 levels.[23] Endoscopic surgery of spine in case of radiculpathy most of the surgeon focus on these preparation and targeted pathology to adequate decompression . Minimal invasive PCF/PCD done first time in two separate cadaver in 2000 cases demonstrating nerve root decompression and bony resection comparing minimal invasive method with open traditional technique.[33,34]. In case of new technique first practice and demonstrate in cadaver for several times. Positioning of patient preparation either spine or prone position depending on which approaches. All the entire surgery is done through fluoroscopic guided and video assisted.

Skin incision is normally $8 \mathrm{~mm}$ to $1.5 \mathrm{~cm}$ depending on location and level of surgery. Either transverse or vertical incision given. Two finger technique/one finger or $\mathrm{K}$ wire blunt used to push the carotid artery and feel the anterior surface of vertebrae. K wire or vertebroplasty needle used to reach the pathology and as a guide tool. Puncture needle complex is used for the posterior superficial part as a target point for decompression. Guide wire and dilators used to puncture hole and is enlarged further by high speed drill burr. Drill system along with trajectory used to monitored in intra-operative endoscopic and fluoroscopic simultaneously. Then a Blunt Hook is used to open posterior wall and later 


\section{International Journal of Science and Research (IJSR) \\ ISSN (Online): 2319-7064}

Index Copernicus Value (2015): 78.96 | Impact Factor (2015): 6.391

palpation to check sufficient decompression done. Endoscopic Kerrison Rongeur used to enlarge the orifice.

Whole of the operation is preformed in a low energy bipolar radiofrequency and the continuous irrigation of $0.9 \mathrm{pc}$ saline solution to maintain the clear visual field. Sometime myelography is also done to see and diagnose and confirm the extruded disc pathology. Dural sac re expansion is done for checking satisfactory neural compression. When hemostasis and drainage is done, all the endoscopic sets are removed and drain fixed for normally 24 hour for recollection and prevent complication like hematoma.

Post operative VAS score and ODI are used to evaluate the pain scoring .Normally cervical collar used for 3-4 weeks .Regular follow up done with radiological parameters for evaluate further. Anterior surgery according to surgeon skill preserve the cervical lordosis, spine stabilization and decompression of the nerve roots. Some surgeon used anterior approach to target to specific structure for decompression and osteophytes removals. Graft installment helped for indirect decompression of neural foramen helping to increase and mobilze the cephalocaudal height space. ACDF helps to relief more than $90 \mathrm{pc}$ of radicular symptoms.

There are some precaution and safety measures to be taken while doing operative approach.

- To prevent the hematoma, we need to try to push the gap between visceral structures and carotid sheath.

- To avoid Vertebral arteries injuries, need to lessen the multiple puncture during targeting the specific structures.

- Aseptic medium to present surgical site infection.

- Avoid too deep puncture when trying to puncture annulus fibrosus, can cause spinal cord injury.

PCN (Percunateous Cervical Nucleoplasty) is minimal invasive intradiscal method for cervical disc herniation pathology. It helps to suction the dissected portion of disc by reducing pressure and volume in the disc. Nucleoplasty works in coblation technology using bipolar radiofrequency energy. It has two phases tissue-ablation and coagulation .During ablation phases a plasma field is generated between the electrodes and tissues. Due to voltage gradients charged particles are accelerated and break molecular bond of the disc nucleus into its constituents molecules and gases. The gases escapes through the needles. There is movement of 0.5 $\mathrm{cm}$ of wand and a zone of thermal coagulation with a radius of $1 \mathrm{~mm}$ created lead to collagen shrinkage .It reduces the intradiscal pressureby removing $1 \mathrm{gm}$ of tissues with minimal thermal damages to the surrounding tissues.[31,32]

\section{Results}

Degeneration of uncovertrebral and zygopophyseal joints lead to foraminal entrapment of spinal nerve roots and disc herniation. Preoperative history, dynamic cervical extensionflexion, PET CT scan and MRI, Endoscopic Cervical Discectomy has replaced many open fused related surgery and bone grafting .It works on placement of retractor , sheath diameter of about $7 \mathrm{~mm}$ incision easy access with proper visualization Fluoroscopic guided endoscopic surgery reduces iatrogenic tissue damage, postoperative pain, disability and return back to work early..Anterior approaches includes discectomy or corpectomy while posterior involves laminectomy with or without fusion and laminoplasty in spinal cord decompress .Open traditional surgical compared to newer minimal invasive surgery was much prolong hospital stay and delay healing.

\section{Discussion}

Depending on the level of nerve involvement signs and symptoms differs. When lesion is in C3-4 level symptoms will be vague neck pain and trapezious pain but in case of $\mathrm{C} 5$, pain occur in the shoulder and radiates to ventral arm even below the elbow. In RA, Atlanto axial $\mathrm{C} 2$ radicular pain can present as eyes and or ear pain and headache which can often me under diagnosed. Spondylosis of the facet joint and herniation of the inter vertebral disc are the causes of nerve root compression which called cervical radiculopathy symptoms..[24] Hypermobility of the facet joint ,ligamentous and bony hyptertrophy cause increase in the size of superior articulating process from distal vertebra lead to compression of the nerve. Intervetebral disc herniation can cause nerve compression from anterior aspect of foramen [25]

Osteophytes are present in cervical radiculopathy due to degeneration, formation of TGF-1 and bFGF factors. Seidler et al. suggested cervical osteophytes present on anterior ventral surface likely to cause esophageal compression, impinge on the hypopharynx due to inflammation, edema, chronic direct irritation .[26,27,28]. Sometime spurling sign and tinel's sign are positive which is called double crush phenomena i.e cervical radiculopathy with peripheral neuropathy.

Stookey (1928)explained the anatomical relationship with clinical symptoms for cervical disc herniation and then Mixter \& Barr used this knowledge to perform laminectomy and dissection to relief pain caused by cervical radiculopathy.[29,30].Minimal invasive Spine surgery can be very safer method for cervical radiculopathy and myleopathy without bone grafting . It allows direct access to adequate decompression of neural elements and other pathology. The discovery of minimally invasive surgery significantly decrease in operative blood loss hospital stay compared with open posterior surgery related to morbidity $[35,36]$.During surgery there is importance of facet preservation in preventing iatrogenic instability of $\mathrm{C}$ spine after Minimal invasive decompression .Zeleblick et.al in his biomechanical studies found that there is significant cervical segment hyper mobility due to resection of more than $50 \mathrm{pc}$ facet joint.[37] Anterior related spine surgery helps to restore cervical lordosis, spine stabilization, decompress the nerve roots and prevent the acceleration of changes at adjacent levels. From the posterior approach multilevel and laminoforaminotomy can be done to decompress cervical nerves causing radiculopathy but in cases of open posterior aggressive dissection of subperiosteal paraspinal muscles lead to post operative morbidity which can cause disability in $18-60 \mathrm{pc}$ of patients[38,40]. Some of the surgeon has demonstrated the cadaver studies on anterior lateral approaches and found it as safer method and less tissues damage to reach the target point .

\section{Volume 6 Issue 3, March 2017




\section{International Journal of Science and Research (IJSR) \\ ISSN (Online): 2319-7064}

Index Copernicus Value (2015): 78.96 | Impact Factor (2015): 6.391

In minimal invasive transforaminal lateral interbody fusion, there is less amount of muscle dissection, less entry points for microbes and dead spaces compared to open traditional spine surgery. [39] There are some possibilities of surgery related complication like horner syndrome, recurrent laryngeal nerve palsy, dysphasia in open and less in endoscopic . Proper planning and preoperative evaluation of VA helps to assist the operating surgeon to avoid vertebral artery injury during anterior surgical approaches to the cervical spines. There can be variation of transverse process and Vertebral arteries. Proper evaluation of CT and MRI for preoperative planning because there can be variation in transverse foramen and VA located relative to bony vertebral landmarks by spinal level and gender. To prevent arterial injuries, it is better to lateral decompress with opening of transverse foramen anterior wall and lateral retraction of vertebral artery under direct visualization [41]

Surgical field is so small and narrow. Therefore manipulation and removal of big and hard excised portions can be difficult. Endoscopic surgery proceeds with continuous saline irrigation as water mediated procedure for decompression which generates hydraulic pressure reducing intraoperative bleeding and infection Radiography is easily and widely available method to visualize osteophytes, facet and unconvertebral arthrosis and narrowing of disc space. A routine cervical stability evaluation done by cervical dynamic $x$ ray which helps to access the stability of cervical vertebrae Spontaneous bony fusion is evaluated by the absence of motion on flexion-extension radiography and by visible disc spaces. CT is useful in distinguishing the extent of a bony spur or foraminal stenosis or the presence of ossification of PLL .Combined CT and MRI images is best tool to perform an accurate assessment of path anatomical structures. $[42,43]$

\section{Conclusion}

Cervical radiculopathy is common problem in orthopedic department. Minimal invasive endoscopic surgery has replaced traditional open surgery due to less blood loss, short hospital stay, minimal tissue damage. Proper visualization transform the spinal surgery and easy to access to the target pathology. Minimal tissue trauma and minimizing the complication related surgery are the goal of current treatment. Understanding surgical anatomy and reevaluation of cases helps to reduce vascular damage in anomaly position.

\section{Abbreviations}

$\begin{array}{ll}\text { CT } & \text { Computerized topography } \\ \text { MRI } & \text { Magnetic resonance imaging } \\ \text { PLL } & \text { Posterior longitudinal ligament } \\ \text { PCN } & \text { Percunateous Cervical Nucleoplasty } \\ \text { PCF /PCD } & \text { Percunateous Cervical Dissectomy and fusion } \\ \text { ACDF } & \text { Anterior Cervical Dissectomy and fusion } \\ \text { VA } & \text { Vertebral arteries } \\ \text { RA } & \text { Rheumatoid arthritis } \\ \text { C3,C5,C2 } & \text { Cervical Spine 3,5,2 } \\ \text { VAS } & \text { Visual analogue scale } \\ \text { ODI } & \text { Oswestry Disability Index } \\ \text { K wire } & \text { Kirschner wires }\end{array}$
PET
Positron emission tomography
NSAIDs Nonsteroidal anti-inflammatory drugs

\section{Declarations}

Ethics approval and consent - Not applicable

Consent for publication -- Not applicable

Availability of data and materials - Not applicable

Competing interests- The authors declare that they have no competing interests

Funding - No grant receive for this research

Authors' contributions - All authors read and approved the final manuscript

\section{Acknowledgements -Not applicable}

\section{References}

[1] Ellenberg MR, Honet JC, Treanor WJ. Cervical radiculopathy. Arch Phys Med Rehabil. Mar 1994;75(3):342-352.

[2] Fouyas IP, Statham PF, Sandercock PA. Cochrane review on the role of surgery in cervical spondylotic radiculomyelopathy. Spinec(Phila Pa 1976). Apr 1 2002;27(7):736-747

[3] Ladenheim SE, Marlowe FI, Dysphagia secondary to cervical osteophytes. Am J Otolaryngol. 1999;20: 1849.

[4] Rana SS, Bhasin DK, Rao C, et al.Thoracic spine osteophyte causing dysphagia. Endoscopy. 2012; 44(2):E19-20.

[5] Fessler RG, Sekhar LN. Atlas of neurosurgical techniques : spine and peripheral nerves. New York: Thieme; 2006

[6] Nardin RA, Patel MR, Gudas TF, Rutkove SB, Raynor EM.Electromyography and magnetic resonance imaging in the evaluation of radiculopathy. Muscle Nerve. Feb 1999;22(2):151-155

[7] Bertalanffy H, Eggert HR Clinical long-term results of anterior discectomy without fusion for treatment of cervical radiculopathy and meylopathy, A follow-up of 164 cases. Acta Neurochir(Wien) ,1988, 90: 127-135

[8] Burman, "Myeloscopy or the direct visualization of the spinal cord and its contents," The Journal of Bone\&Joint Surgery, 1931; vol. 13, no. 4, pp. 695-696

[9] Y. Ooi, Y. Satoh, K. Mikanagi, et al. Myeloscopy, No to shinkei, 1977 vol. 29, no. 5, pp. 569-574.

[10] Stookey B , Compression of the spinal cord due to ventral extradural cervical chondromas. Arch Neurol Psych 1928;20:275-278

[11] Mixter WJ, Barr JS , Rupture of the intervertebral disc with involvement of the spinal canal. N Engl J Med 1934;211:210-215

[12] Robinson RA, Walker AE, Ferlic DC, et al. The results of anterior interbody fusion of the cervical spine. J Bone Joint Surg Am,1962; 44:1569-1587 


\section{International Journal of Science and Research (IJSR) \\ ISSN (Online): 2319-7064 \\ Index Copernicus Value (2015): 78.96 | Impact Factor (2015): 6.391}

[13] Ralph b. Cloward, .Honolulu, et al.Hawaii the anterior approach for removal of ruptured cervical disks, J. Bone Jt. Surg., 1958, 4O-A: 607-623

[14]H. C. Jacobeus, The practical importance of thoracoscopy in surgery of the chest, Surgery, Gynecology \& Obstetrics, , 1921;vol. 32, pp. 493-500

[15] J.-Y. Lee, M. Lo"hr, P. Impekoven, et al.Small keyhole transuncal foraminotomy for unilateral cervical radiculopathy Acta Neurochir (Wien), 2006 ;148: 951958

[16] Jho HD ,Microsurgical anterior cervical foraminotomy for radiculopathy: a new approach to cervical disc herniation. J Neurosurg ,1996;84: 155-160

[17] Kim JG, Kim SW, Lee SM, et al. Surgical result of the combined anterior and posterior approach in treatment of cervical spondylotic myelopathy, J Korean Neurosurg,, 2006;Soc 3 : 188-191

[18] Korinth MC, Kruger A, Oertel MF, et al. Posterior foraminotomy or anterior discectomy with polymethyl methacrylate interbody stabilization for cervical soft disc disease: results in 292 patients with monoradiculopathy, Spine Phila $\mathrm{Pa}$ 1976;. may 15 2006;31(11):1207-1214

[19] Onik G, Helms CA, Ginsburb L , et al.Percutaneous lumbar discectomy using a new aspiration probe. AJNR, 1985; 144:290-293

[20] S. L. Parker, S. K. Mendenhall, D. N. Shau et al., Minimally invasive versus open transforaminal lumbar interbody fusion(tlif) for degenerative spondylolisthesis: comparative effectiveness and cost-utility analysis,"World Neurosurgery, 2013

[21] Burman, "Myeloscopy or the direct visualization of the spinal cord and its contents," The Journal of Bone\&Joint Surgery, 1931; vol. 13, no. 4, pp. 695-696

[22] Y. Ooi, Y. Satoh, K. Mikanagi, et al. Myeloscopy, No to shinkei, 1977 vol. 29, no. 5, pp. 569-574.

[23]Zhong-Liang Deng, Lei Chu, Liang Chen ,et.al, Anterior transcorporeal approach of percutaneous endoscopic cervical discectomy for disc herniation at the C4-C5 levels: a technical note, The Spine Journal 16 (2016) 659-666

[24]Benzel EC, lubelski D,Healy,et al.Reoperation rates after anterior cervical discectomy and fusion versus posterior cervical foraminotomy: a propensity-matched analysis, spine $\mathrm{j}_{\mathbf{z}} 2015$ Jun 1;15(6):1277-83.

[25]Bush K, Chaudhuri R, Hillier S, et al. The pathomorphologic changes that accompany the resolution of cervical radiculopathy. A prospective study with repeat magnetic resonance imaging. Spine Phila Pa 1976;.Jan 15 1997;22(2):183-186

[26] Ladenheim SE, Marlowe FI, Dysphagia secondary to cervical osteophytes. Am J Otolaryngol. 1999;20: 1849.

[27] Seidler TO, Pe`rez Alvarez JC, Wonneberger K, et al. Dysphagia caused by ventral osteophytes of the cervical spine,Clinical and radiographic findings. Eur Arch Otorhinolaryngol,2009;266:285-91

[28] Rana SS, Bhasin DK, Rao C, Gupta R, Nagi B, Singh K. Thoracic spine osteophyte causing dysphagia. Endoscopy. 2012; 44(2):E19-20.
[29] Stookey B , Compression of the spinal cord due to ventral extradural cervical chondromas. Arch Neurol Psych 1928;20:275-278

[30] Mixter WJ, Barr JS , Rupture of the intervertebral disc with involvement of the spinal canal. $\mathrm{N}$ Engl J Med 1934;211:210-215

[31] Sim SE, Ko ES, Kim DK et al (2011) The results of cervical nucleoplasty in patients with cervical disc disorder: a retrospective clinical study of 22 patients. Korean J Pain 24:36-43

[32] Timmermann J, Hahn M, Krueger K (2011) Short-term followup:micro-invasive therapy of the cervical herniated disk by percutaneous nucleotomy. J Back Musculoskelet Rehabil 24:89-93

[33] Burke TG, Caputy A. Microendoscopic posterior cervical foraminotomy: a cadaveric model and clinical application for cervical radiculopathy. J Neurosurg 2000;93(1 Suppl):126-9.

[34]Roh SW, Kim DH, Cardoso AC, et al. Endoscopic foraminotomy using MED system in cadaveric specimens. Spine 2000;25: 260-4.

[35] Fessler RG, Khoo LT. Minimally invasive cervical microendoscopic foraminotomy: an initial clinical experience. Neurosurgery 2002;51(5 Suppl):S37-45

[36] Adamson TE. Microendoscopic posterior cervical laminoforaminotomy for unilateral radiculopathy: results of a new technique in 100 cases. J Neurosurg 2001;95(1 Suppl):51-7

[37]Zdeblick TA, Zou D, Warden KE, et al. Cervical stability after foraminotomy. A biomechanical in vitro analysis. J Bone Joint Surg Am 1992;74:22-7.

[38]Ducker TB, Zeidman SM. The posterior operative approach for cervical radiculopathy. Neurosurg Clin N Am. Jan 1993;4(1):61

[39] S. L. Parker, S. K. Mendenhall, D. N. Shau et al., Minimally invasive versus open transforaminal lumbar interbody fusion(tlif) for degenerative spondylolisthesis: comparative effectiveness and cost-utility analysis,"World Neurosurgery, 2013

[40] Benny B, Azari P, Briones D. Complications of cervical transforaminal epidural steroid injections. Am J Phys Med Rehabil. Jul 2010;89(7):601-607

[41] Steven W Malik, Brian D. et al .Location of the transverse foramen in the subaxial cervical spine in a Young asymptomatic Population, SPINE, 2010;Volume 35, Number 12, pp E514-E519

[42] Katsumi Y, Honma T, Nakamurs T ,et al. Analysis of cervical instability resulting from laminectomies for removal of spine cord tumor. Spine ,1989;14:11711176

[43] Yvonne Yi-Na Bender, Gerd Diederichs, et al. Thula Cannon Walter, Differentiation of osteophytes and disc herniations in spinal radiculopathy using susceptibilityweighted magnetic resonance imaging, Investigative Radiology, 2016; Volume 00, Number 00, Month 